
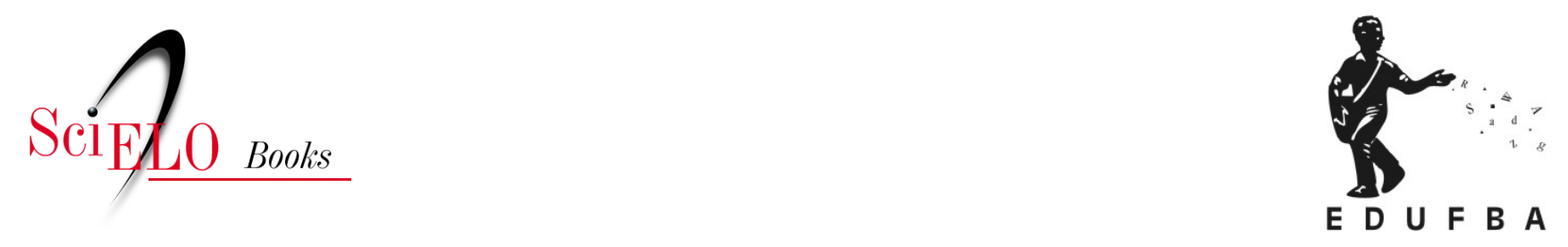

\title{
O auxílio-acidente e os acidentes de trabalho no Brasil
}

\author{
Carlos Eduardo Soares de Freitas
}

\section{SciELO Books / SciELO Livros / SciELO Libros}

FREITAS, C.E.S. O auxílio-acidente e os acidentes de trabalho no Brasil. In: Auxilio-acidente e saúde do trabalhador [online]. Salvador: EDUFBA, 2018, pp. 101-135. ISBN: 978-85-232-1875-1. https://doi.org/10.7476/9788523218751.0005

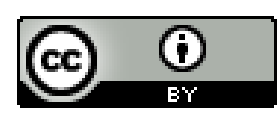

All the contents of this work, except where otherwise noted, is licensed under a Creative Commons Attribution $\underline{4.0 \text { International license. }}$

Todo o conteúdo deste trabalho, exceto quando houver ressalva, é publicado sob a licença Creative Commons Atribição 4.0. 


\section{0 auxílio-acidente e os acidentes de trabalho no Brasil}

O histórico recente dos dados públicos da previdência social revela questões fundamentais sobre a realidade dos acidentes e doenças do trabalho no Brasil, ao tempo em que levanta a necessidade de pesquisas interdisciplinares nesse campo na busca de esclarecimentos de assuntos relevantes, como os efeitos das subnotificações. Neste capítulo, estuda-se algumas dessas questões, a exemplo dos reflexos da adoção de diferentes políticas governamentais que são percebidos por meio de eventuais aumentos ou reduções nas concessões de benefícios acidentários. Ademais, a saúde do trabalhador é tomada como objeto de reflexão social sobre o mundo do trabalho e dos modelos de economia política implantados no país. Nessa linha, o estudo dos benefícios acidentários (o auxílio-doença acidentário, o auxílio-acidente, a aposentadoria por invalidez e a pensão por morte decorrente de acidente de trabalho) demonstra a importância das investigações sobre as relações de trabalho na contemporaneidade, em especial no âmbito do direito ambiental do trabalho. 


\section{A sociedade conhece o auxílio-acidente?}

Até aqui, estudamos o quanto o auxílio-acidente é um benefício diferenciado em relação aos demais que integram o elenco de direitos previdenciários do RGPS ou dos regimes próprios. Analisamos também a importância do auxílio-acidente como reparação aos segurados que sofrem acidentes ou doenças que os sequelam de maneira a afetar sua capacidade produtiva no trabalho. No entanto, ao verificar a quantidade de benefícios concedidos conforme os Anuários Estatísticos da Previdência Social, e apenas por esse critério sabidamente limitado, somos levados a concluir que embora os acidentes de trabalho no Brasil sejam muito numerosos, seus efeitos não se apresentam formalmente com tanta intensidade no que se referem à gravidade das suas consequências.

Trata-se de conclusão que pode não refletir a realidade das relações de trabalho e os efeitos dos acidentes dela decorrentes, ainda mais se constatamos a inexistência de políticas reconhecidamente eficazes de prevenção a acidentes de trabalho, seja por parte dos governos (federal, estaduais e municipais), das empresas ou mesmo dos sindicatos das categorias profissionais, considerando as prioridades unicamente salariais em pautas de reivindicações encaminhadas às negociações coletivas.

Assim, mesmo ponderando que o benefício sob análise abrange acidentes que não são do trabalho, duas perguntas podem ser formuladas sobre a relação entre concessões de auxílio-acidente e acidentes de trabalho: a quantidade de sequelados com capacidade de trabalho reduzida parcial e permanentemente registrada nos anuários da previdência social reflete a realidade? Considerando o desconhecimento como fator que distancia o sujeito do seu direito, até que ponto o auxílio-acidente é um benefício conhecido dos trabalhadores brasileiros? A partir dos dados dos anuários, de 
pesquisas sobre acidentes e das necessárias reflexões jurídicas, tentaremos responder a essas questões.

\section{Os dados da Previdência Social}

Os anuários estatísticos do regime geral da previdência social, consolidados pelo Dataprev (Empresa de Tecnologia e Informações da Previdência Social), constituem-se em notável tentativa de dar publicidade a aspectos essenciais da seguridade social do país e da própria sociedade brasileira.

A consolidação de dados registrados pelo INSS revela a extensão da previdência pública e com isso sua importância no acesso a rendimentos por parte da população beneficiária. São registros apurados dos trabalhadores formais com filiação ao INSS, o que equivale, historicamente, a menos da metade da população economicamente ativa no país. Estão fora do cômputo dos anuários os servidores públicos (federais, estaduais e muitos municipais) com regimes próprios, os trabalhadores autônomos informais e os empregados sem registros.

Mesmo no universo ao qual se propõe atingir, esses dados não retratam integralmente a realidade, e um dos fatores que sugere esse distanciamento é a subnotificação, sob a forma do não registro ou do falseamento de registro de um evento que teria determinadas implicações previdenciárias.

Assim, a ausência do registro ou da formalização de algo que não expresse a realidade, faz com que os dados indiquem equívocos. Mas mesmo insuficiente e sem retratar integralmente a realidade dos acidentes de trabalho no Brasil, a consolidação dos dados feitos pela Previdência Social ainda se coloca como a mais completa, dentre as demais formas de apuração, como o Sistema de Informações Hospitalares (SIH), o Sistema de Informações sobre Mortalidade (SIM) e o Relação Anual de Informações Sociais 
(RAIS). A esse respeito, análise muito bem feita sobre os dados dos acidentes de trabalho foi elaborada por Bernadette Cunha Waldvogel (2OII), que não apenas comparou os dados das diferentes fontes (Dataprev, SIH, SIM e RAIS), mas também formulou o que chamou de integração de bases de dados, a partir de uma experiência realizada no Estado de São Paulo entre os anos I997 e I999.

Os registros públicos sobre relações de trabalho são fundamentais como dados históricos, o que amplia ainda mais sua relevância. As condições de trabalho nos períodos iniciais da Revolução Industrial e seus efeitos nas vidas dos operários, por exemplo, foram mundialmente divulgadas em obras que tiveram como fontes as informações dos então fiscais públicos do trabalho. É o que se verifica em Marx (1988), a partir do depoimento de médico sensível às condições de trabalho:

Trabalhar até a morte está na ordem do dia, não apenas na oficina das modistas, mas em milhares de outros lugares, na verdade em cada lugar onde o negócio floresce. (...) Permita-nos tomar o exemplo do ferreiro. Se se deve acreditar nos poetas, não existe nenhum homem tão cheio de vida, nem mais alegre que o ferreiro. Ele se levanta cedo e tira faíscas ao sol; ele come, bebe e dorme como nenhum outro homem. Considerado o aspecto puramente físico, ele se encontra com trabalho moderado, de fato numa das melhores posições humanas. Porém, seguimo-lo à cidade e vemos que carga de trabalho é lançada sobre esse homem forte, e qual posição ocupa na lista de mortalidade em nosso país. Em Marylebone" (um dos maiores bairros de Londres) "os ferreiros morrem na proporção de 3I por I ooo anualmente, ou ir acima da média de mortalidade dos homens adultos na Inglaterra. A ocupação, uma arte quase instintiva da humanidade, em si e para si irrepreensível, torna-se, em virtude do excesso de trabalho, destruidora do homem. Ele pode vibrar tantas pancadas por dia, andar tantos passos, respirar tantas vezes, realizar tanto trabalho e viver em média, digamos, 50 anos. Obrigam-no a vibrar tantas pan- 
cadas a mais, a andar tantos passos a mais, a respirar durante o dia mais freqüentemente, e tudo junto a aumentar assim diariamente de $\mathrm{I} / 4$ seu dispêndio vital. Ele realiza a tentativa, e como resultado realiza, num período limitado, I/4 a mais de trabalho e morre aos 37 anos e não aos 50. (RICHARDSON, I863 apud MARX, 1988)

E o que investiga Engels, com base em relatórios e registros públicos sobre os efeitos da exploração capitalista na vida dos operários ingleses:

O relatório sobre o estado de saúde das classes trabalhadoras contém indicações que apontam este mesmo fato. Em Liverpool. A duração média de vida em I840 para as classes superiores (gently, professiona men, etc.) era de 35 anos, a dos homens de negócios e dos artesãos abastados, 22 aos, a dos operários, jornaleiros e domésticas em geral de apenas i5 anos. Os relatórios parlamentares contêm muitos dados análogos.

É a assustadora mortalidade infantil da classe operária que aumenta a taxa de mortalidade. O frágil organismo de uma criança é o que oferece menor resistência aos efeitos desfavoráveis de um modo de vida miserável; o estado de abandono em que frequentemente se encontra quando os pais trabalham, ou quando um deles morreu, não tarda a fazer-se sentir cruelmente; não é de causar espanto se, por exemplo, em Manchester, segundo o relatório que acabamos de citar, mais de $57 \%$ dos filhos de operários morrem antes de terem atingido os 5 anos de idade, enquanto que entre as crianças das classes burguesas a proporção de falecimentos não é senão de $20 \%$ e a média de todas as classes nas zonas rurais não atinge $32 \%$. (ENGELS, 1985, p. I27)

No Brasil contemporâneo, o regime geral da previdência social continua a ser a melhor experiência de previdência pública, em termos de apuração de informações e dados sobre benefícios e segurados. Os regimes próprios ainda não se ocuparam da orga- 
nização metódica desses dados, o que se coloca como necessidade premente para que a sociedade conheça a realidade das condições de trabalho dos servidores públicos, quais os acidentes e doenças que mais os afligem, que medidas devem ser adotadas para a superação dos eventos e quais os benefícios adequados que devem ser introduzidos nas respectivas regulamentações.

Um pouco mais pode ser dito sobre a insuficiência dos dados dos anuários da previdência social consolidados pelo Dataprev: algumas das informações ali contidas partem de registros oriundos da iniciativa do empregador, em especial os eventos relacionados a acidentes do trabalho. O preenchimento da Comunicação de Acidente do Trabalho (CAT) não é exclusivo do empregador e até mesmo a própria vítima poderá fazê-lo, mas a experiência empírica e a narrativa dos trabalhadores mostram que o INSS atribui maior veracidade quando é o empregador que o faz. Se o INSS busca impedir simulações dos trabalhadores, acaba por criar um ambiente propício à omissão dos empregadores, que eventualmente deixam de registrar um acidente de trabalho como tal, como forma de se livrar da responsabilidade de indenizar a ser reclamado posteriormente.

Conforme o Anuário Estatístico de 20II, as omissões verificadas pelo INSS quanto ao não registro de CATs revelam números duvidosos que realçam a tentativa de falseamento de dados junto ao INSS: em termos de idade dos segurados acidentados, entre os trabalhadores até 24 anos, há uma equiparação aproximada entre registros e não registros de CATs, mas à medida que o trabalhador avança na idade, menor o número de registros de Comunicações de Acidentes do Trabalho. Exemplo: entre trabalhadores de 40 a 44 anos, os acidentes não registrados em CAT superam em quase três vezes os acidentes registrados nessa faixa etária.

No caso de auxílio-acidente decorrente de acidente de trabalho, a subnotificação afetaria seus registros, uma vez que o segurado não seria afastado, inicialmente, com o recebimento do auxílio- 
-doença acidentário, mas do auxílio-doença comum; e cessado o auxílio-doença comum, o INSS certamente não lhe deferiria o auxílio-acidente decorrente de acidente de trabalho.

Afastamentos ao serviço que duram menos de 15 dias, decorrentes de acidentes ou doenças do trabalho, devem também ser registrados, mas como não provocam a concessão do auxílio-doença, a não ser na hipótese de se acumularem vários períodos curtos que somem mais de I5 dias, tendem à subnotificação. E, com isso, não são registrados nos anuários estatísticos da previdência social.

Outro descompasso entre os dados e a realidade se dá na ilícita informalidade dos contratos de trabalho dos empregados. Trata-se da situação em que empregadores deixam de registrar seus empregados conforme obrigação trabalhista, e com isso retiram dos trabalhadores o acesso aos direitos previdenciários. Esses, mesmo que tipicamente segurados obrigatórios, deixam de constar como tais em razão do não registro trabalhista (anotações na Carteira de Trabalho e Previdência Social - CTPS, com a consequente inadimplência dos recolhimentos ao INSS, e encaminhamento pelo empregador da RAIS).

Assim, se um trabalhador sofre um acidente de trabalho, sem que tenha o devido registro como empregado, poderá não gozar do direito ao auxílio-doença, caso o seu afastamento se prolongue por mais de I5 dias. A extensão dos efeitos deletérios do não registro do empregado poderá ser imensa, a depender da ocorrência de eventos que provoquem o seu afastamento compulsório do serviço.

Segundo informações dos anuários, há uma queda no número de registros de acidentes de trabalho no Brasil. Investigamos os dados de quatro atividades econômicas com presença provavelmente fortalecida no contexto atual: o das indústrias extrativistas; da construção de edifícios e infraestruturas; do comércio varejista não especializado e de produtos alimentícios, bebidas e fumo; e do transporte ferroviário, metroviário e de rodoviário de passageiros. 
A comparação entre os anos de 2009 e 2010 nesses setores indicam queda nos números absolutos de acidentes de trabalho, embora a variação da taxa de letalidade (por I.ooo acidentes) tenha aumentado de um ano para o outro. Isso significa que redução de acidentes pode não implicar em redução de mortes. Embora os setores acima indicados apontem aumento de letalidade, verifica-se, no geral, redução no número de mortes em acidentes de trabalho. Atente-se que são dados registrados nos anuários, que não retratam integralmente a realidade.

Há também atividades em que o trabalho não aparece tanto quanto outros fatores, o que provoca distorções nos registros de acidentes de trabalho. É o caso dos acidentes de trânsito. Duas pesquisas realizadas no Instituto de Saúde Coletiva da Universidade Federal da Bahia sugerem que os números reais podem ser outros, mais elevados que os anotados nos anuários: a tese de doutorado intitulada "Trabalho precário e morte por acidente de trabalho: a outra face da violência e a invisibilidade do trabalho", de Letícia Coelho da Costa Nobre; e a dissertação de mestrado "Ases do asfalto: vitimização e responsabilização no trabalho de motoboys de Salvador", de Maria Angélica Riccio Oliveira.

Outro estudo, "Trabalho, violência e morte em Campinas, São Paulo, Brasil”, de Élida Azevedo Hennington, Ricardo Cordeiro e Djalma de Carvalho Moreira Filho, mostra a subnotificação dos acidentes de trabalho fatais em eventos relacionados a mortes violentas. Segundo os pesquisadores, em I99I os homicídios em Campinas (SP) não apenas ultrapassaram os acidentes de trânsito como principal causa de morte violenta, mas se tornaram a segunda causa de mortes, perdendo apenas para as doenças isquêmicas do coração. Da leitura desses estudos, é possível concluir que um número significativo de acidentados do trabalho deixou de ser registrado como tal, seja pela informalidade na relação de trabalho seja pela circunstância do acidente, em especial quando decorre do trânsito. 
Especificamente sobre o trabalho de motoboys, é notório o crescimento da atividade em todo o país e a relação tipicamente desregrada com seus empregadores reais ou com aqueles para os quais prestam serviços. Muitos deles são empregados de fato, mas sem registros formais. Assim, os acidentes que ocorrem são anotados exclusiva e oficialmente como de trânsito, sem menção à relação com o trabalho. Em Salvador (Bahia), os motoboys pesquisados são, predominantemente, do sexo masculino, com idade acima de 30 anos, faixa etária que já foi menor anteriormente, sendo comum a informalidade dos vínculos. (OLIVEIRA, 2006)

O Mapa da Violência 20II (WAISELFISZ, 20II) também expôs dados impressionantes sobre mortes no trânsito entre 1998 e 2008, que concluem pela alta ocorrência de acidentes entre jovens de I9 a 22 anos. Reproduzo, abaixo, dados de dois quadros do Mapa (com a exclusão da coluna de variações, que constam das tabelas originais), a primeira com a população total por categoria, e a segunda específica para a população jovem:

Tabela 1 - Quantidade de óbitos em acidentes de trânsito por categoria (Brasil, 1998/2008)

\begin{tabular}{l|l|l|l|l|l|l|l}
\hline Categoria & 1998 & 2000 & 2002 & 2004 & 2006 & 2007 & 2008 \\
\hline Pedestre & 20.314 & 13.643 & 14.341 & 13.966 & 12.956 & 12.157 & 12.157 \\
\hline Ciclista & 717 & 1.238 & 1.788 & 1.908 & 2.130 & 2.111 & 2.072 \\
\hline Motociclista & 1.894 & 3.910 & 5.440 & 6.961 & 9.191 & 10.392 & 11.471 \\
\hline Automóvel & 6.628 & 8.262 & 9.069 & 9.875 & 9.754 & 10.218 & 10.420 \\
\hline Caminhão & 630 & 1.042 & 1.116 & 1.356 & 1.341 & 1.354 & 1.264 \\
\hline Ônibus & 186 & 199 & 195 & 291 & 300 & 234 & 230 \\
\hline Outros & 521 & 701 & 805 & 749 & 696 & 735 & 660 \\
\hline Total & 30.890 & 28.995 & 32.753 & 35.105 & 36.367 & 37.407 & 38.273 \\
\hline
\end{tabular}

Fonte: Caderno Complementar do Mapa da Violência 2011: Acidentes de Trânsito, Tabela 2.4 . 
Tabela 2 - Quantidade de óbitos em acidentes de trânsito por categoria população jovem (Brasil, 1998/2008)

\begin{tabular}{l|l|l|l|l|l|l|l}
\hline Categoria & 1998 & 2000 & 2002 & 2004 & 2006 & 2007 & 2008 \\
\hline Pedestre & 3.346 & 1.991 & 2.035 & 1.910 & 1.566 & 1.464 & 1.294 \\
\hline Ciclista & 210 & 293 & 405 & 348 & 397 & 381 & 363 \\
\hline Motociclista & 921 & 1.651 & 2.248 & 2.850 & 3.634 & 4.063 & 4.447 \\
\hline Automóvel & 1.915 & 2.067 & 2.334 & 2.383 & 2.334 & 2.319 & 2.269 \\
\hline Caminhão & 165 & 194 & 222 & 230 & 198 & 189 & 196 \\
\hline Ônibus & 15 & 38 & 38 & 59 & 62 & 42 & 31 \\
\hline Outros & 129 & 114 & 158 & 112 & 93 & 113 & 70 \\
\hline Total & 6.701 & 6.348 & 7.440 & 7.891 & 8.283 & 8.571 & 8.669 \\
\hline
\end{tabular}

Fonte: Caderno Complementar do Mapa da Violência 2011: Acidentes de Trânsito, Tabela 2.9.

Além dos motociclistas, verifica-se um número alto de acidentes entre condutores ou usuários de caminhões, veículos utilizados exclusivamente para o labor, em bicicletas, muito usadas como equipamento para o deslocamento de trabalhadores, e entre pedestres, provavelmente em movimentações para ou de volta ao trabalho. É possível que muitas dessas mortes não tenham sido registradas como acidentes de trabalho. Por outro lado, são acidentes que sugerem que parte dos sobreviventes tenha ficado com sequelas relevantes, com efeitos na produtividade laboral, com incapacidade parcial e permanente. Segundo números da Organização Mundial da Saúde divulgados pelo Ministério da Saúde, em todo o mundo "I.3 milhão de pessoas perdem suas vidas anualmente do trânsito e até 50 milhões sobrevivem feridas".

1 Informação disponível em: <http://portal.saude.gov.br/portal/saude/profissional/visualizar_texto.cfm?idtxt=37121>. 
São números que dão a dimensão do problema. Nesses casos, provavelmente muitas das vítimas também deixaram de ser registradas pela Previdência Social como acidentadas do trabalho; embora se trate de problema de conhecimento público, conforme reconhece o próprio governo federal, que em 20 I lançou a política conjunta dos Ministérios da Saúde e das Cidades, intitulada "Pacto Nacional pela Redução dos Acidentes no Trânsito - Pacto pela Vida”. Preocupação também localizada entre os "Informes" publicados pelo Ministério da Previdência Social. ${ }^{2}$ (TODESCHINI, 2008)

Os estudos sobre mortes violentas e motoboys são dois bons exemplos que indicam o quanto os dados mais próximos da realidade estão também distantes dela.

Segundo reportagem publicada no jornal Folha de São Paulo (edição de 09/05/2012), a Divisão de Saúde do Trabalhador da Vigilância Sanitária do Estado de São Paulo, conforme dados do Sistema de Informações de Agravos de Notificação (Sinam), registrou 55,4 mil acidentes de trabalho em 20II, com 464 mortes. Há de se considerar a possível precariedade na coleta desses registros e levar em conta a dificuldade de se apurar os números dos portadores de sequelas, isto é, dos trabalhadores que têm sua capacidade produtiva afetada permanentemente por causa dos acidentes, de maneira que os dados sobre acidentes mostram, em geral, parte da tragédia e dos seus efeitos.

Há um conjunto de fatores que mantém esse distanciamento e dificultam a precisão de dados sobre os acidentes do trabalho no país. Além dos já mencionados, podem-se citar mais alguns relacionados a políticas públicas:

2 Neste livro, mantenho a referência ao Ministério da Previdência Social em relação ao período de apuração ou divulgação de dados, ponderando que após o golpe parlamentar de 31/08/2016, o Ministério da Fazenda incorporou a pasta da previdência social. (DELGADO, 2016) 
a. a precariedade de um acompanhamento público dos acidentes de trabalho, longe da necessária eficiência, é identificada na claudicante articulação da Rede Nacional de Atenção Integral à Saúde do Trabalhador (RENAST), no âmbito do SUS (LEÃO; VASCONCELOS, 2OII);

b. a prioridade da fiscalização do Ministério do Trabalho e Emprego na formalização de contratos e de depósitos do FGTS, em detrimento ao acompanhamento das condições de trabalho;

c. a ausência generalizada de delegacias de polícia diretamente relacionadas a acidentes de trabalho.

Por outro lado, a sociedade tenta chegar aos dados sobre seus acidentados e doentes do trabalho de maneira quase artesanal, especialmente através de sindicatos (nem todos) interessados em melhorias das condições de trabalho e de associações específicas vinculadas a determinados prejuízos ou produtos agressivos à saúde, como as dos expostos ao amianto e a dos contaminados pelo chumbo e cádmio, apenas para ficar em território baiano.

\section{Análise dos números sobre o auxílio-acidente}

O tratamento dado ao auxílio-acidente não tem sido conduzido como parte de uma política permanente dos governos brasileiros, isto é, como uma "política de Estado" na previdência social pública. As diferenças verificadas nas médias de concessões de cada governo (de 1980 a 20II) revelam que a autarquia previdenciária adotou condutas específicas a cada mudança na chefia do poder executivo. Os números dos anuários permitem outras conclusões: após I99I, ano da Lei no 8.213, as concessões aumentaram, talvez por não existir mais o auxílio-suplementar, que de alguma forma atendia parte dos potenciais beneficiários do auxílio-acidente.

Os dados estatísticos da Previdência Social ajudam a perceber a movimentação das concessões dos dois distintos auxílios-aciden- 
tes. O mais recente, criado no governo Fernando Henrique Cardoso, e que não se refere ao trabalho, contou com uma média anual inicial de 836 concessões no governo Cardoso, ampliou-se para 3.669 no governo Luiz Inácio Lula da Silva, até chegar à média anual estabilizada no governo Dilma Rousseff. Já o auxílio-acidente relacionado ao trabalho teve um crescimento menos acelerado. Para melhor compreender os números de concessões dessa modalidade do auxílio-acidente, e pensá-los politicamente, é possível articular comparações com os outros benefícios acidentários ${ }^{3}$ (auxílio-doença, aposentadoria por invalidez e pensão por morte), com a ajuda da visualização gráfica abaixo.

Gráfico 1 - Evolução de benefícios acidentários: comparativo de médias anuais, por governos (F.H.C., Lula e Rousseff)

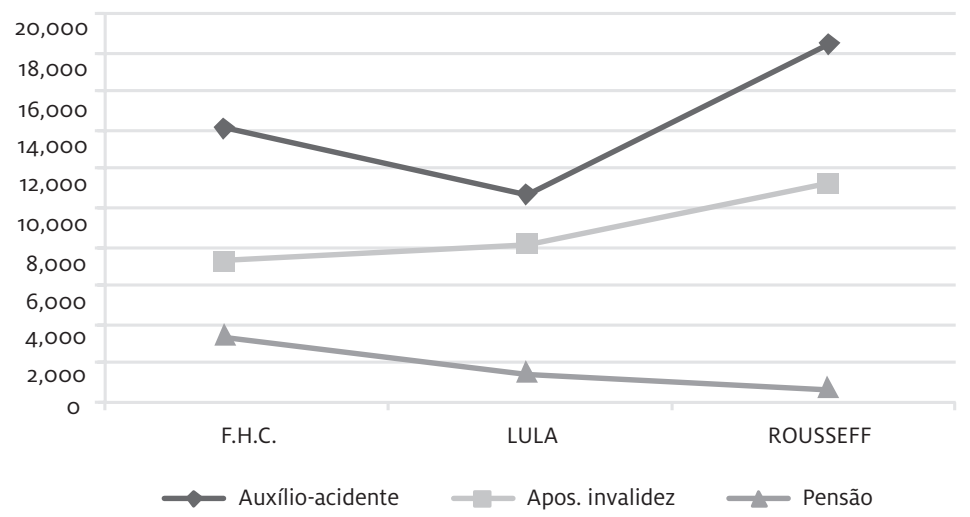

Fonte: Anuários estatísticos da Previdência Social.

3 Durante a vigência da Lei nº 6.367/76, havia ainda o auxílio-suplementar, que também beneficiava os acidentados do trabalho, mas optamos por manter os dados apenas do auxílio-acidente. 
Gráfico 2 - Média anual de concessões do auxílio-doença acidentário, por governos

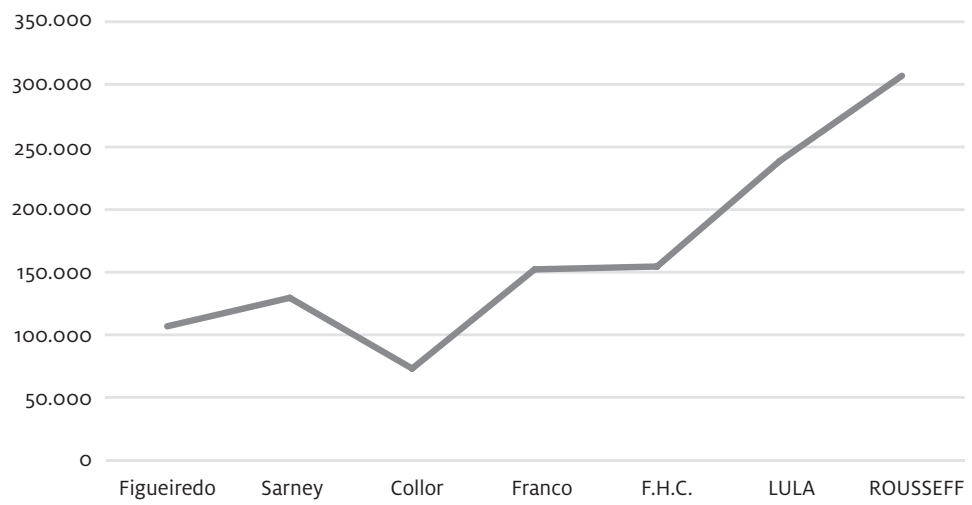

Fonte: Anuários estatísticos da Previdência Social.

Tabela 3 - Média anual de concessões de benefícios relacionados a acidentes do trabalho, por tipo e por governo (Brasil, 1980 a 2014)

\begin{tabular}{l|l|l|l|l|l|l|l}
\hline & Figueiredo & Sarney & Collor & Franco & F.H.C. & Lula & Rousseff \\
\hline $\begin{array}{l}\text { Auxílio- } \\
\text { acidente }\end{array}$ & 10.555 & 8.779 & 8.995 & 11.615 & 14.116 & 10.671 & 18.381 \\
\hline $\begin{array}{l}\text { Apos. } \\
\text { Invalidez }\end{array}$ & 5.554 & 5.530 & 4.246 & 4.274 & 7.299 & 8.077 & 11.268 \\
\hline $\begin{array}{l}\text { Auxílio- } \\
\text { doença }\end{array}$ & 107.379 & 130.377 & 73.061 & 152.570 & 153.881 & 237.936 & 306.684 \\
\hline Pensão & 5.371 & 5.878 & 4.738 & 5.279 & 3.299 & 1.375 & 568 \\
\hline
\end{tabular}

* Os dados dos governos de Figueiredo, Collor e Franco não foram registrados integralmente pela Previdência Social.

Fonte: Anuários estatísticos da Previdência Social.

A aderência entre o auxílio-doença acidentário e o auxílio-acidente decorrente de acidente de trabalho, concedido administrativamente após constatada a sequela que importe em incapacidade 
parcial e permanente em seguida à cessação do primeiro, permite algumas comparações a partir dos dados coletados. São dados que oferecem muitas possibilidades de discussões e hipóteses, a exemplo do que abaixo são expostas:

I. O número de concessões de auxílio-doença previdenciário (B3I) no último ano do governo Sarney apresentou uma queda de $6 \%$ dos números registrados no primeiro ano daquele governo, enquanto que o número de concessões de auxílio-doença acidentário (B9I) no último ano do governo Sarney correspondeu a $60 \%$ das concessões no primeiro ano. Com isso, mesmo que tenha ocorrido um número significativo de acidentes de trabalho, seus registros foram reduzidos.

Ainda nesse passo, o número de concessões de auxílio-doença previdenciário (B3I), do início ao final do governo Cardoso, aumentou $120 \%$, já o auxílio-doença acidentário (B9I) teve aumento de apenas $4,4 \%$. Os dados no governo Lula inverteram-se: o auxílio-doença previdenciário (B3I) aumentou 38,6\% e o auxílio-doença acidentário (B9I), I29\%. A discrepância entre os números nos diferentes governos revela uma descontinuidade de políticas de registros dos eventos (acidentários ou não), pelo INSS, sob a forma de eventuais tecnologias que registram com maior fidelidade os eventos relacionados a acidentes de trabalho, como o nexo técnico epidemiológico no segundo governo Lula.

2. A média anual de concessões de auxílio-doença acidentário durante o governo Fernando Henrique Cardoso (I53.88I) é menor que o número de concessões desse benefício no último ano do governo José Sarney. A média anual de concessões de auxílio-doença acidentário durante o governo Lula foi de 237.936, ou uma vez e meia a média anual no governo Cardoso. Dados que também sugerem orientações, ao longo do governo Fernando Henrique Cardoso, para forçar um menor registro de acidentes, com tendência ao falseamento dos dados. 
Curiosamente, documento qualificado como confidencial, produzido pela Agência Brasileira de Inteligência (ABIN), datado de I999, ${ }^{4}$ relata discussões ocorridas em Simpósio sobre Saúde do Trabalhador, com a presença de especialistas de instituições oficiais, realizado em agosto daquele ano e que apurou que o "número de acidentes de trabalho por ano continua alto na Bahia". O registro de informação tão elementar, obtido de maneira secreta via ABIN e em pleno período de democracia formal, sugere que o governo Cardoso se ocupava em monitorar a divulgação e as preocupações em torno dos dados dos acidentes de trabalho. Duas reflexões são necessárias: primeiro, a forma inusitada para chegar àquela informação, quando a Previdência Social já tabulava, então, os números de doenças e acidentes do trabalho e os anunciava publicamente em seus Anuários; e segundo, a própria política da Inteligência, que se dirigia a observar e anotar atividades formais, que aparentemente não estariam no escopo do órgão.

3. A adoção do nexo técnico epidemiológico, introduzido pela Lei $\mathrm{n}^{0}$ II.430, de dezembro de $2006,{ }^{5}$ aumentou a quantidade de concessões de auxílio-doença a partir de 2007 (governo Lula), o que provavelmente provocou, anos depois, um maior número de auxílios-acidentes e aposentadorias por invalidez, em decorrência da transformação daquele primeiro benefício temporário. De uma maneira geral, é possível inferir que quanto maior o número de afastamentos previdenciários por acidentes de trabalho,

4 Trata-se do documento denominado "RELATÓRIO DE INTELIGÊNCIA N\%214/9101/ABA/SSI/ CM/PR/Í 6 SET 1999”, registrado sob o código “BR_RJANRIO_H4_O_AGP_ABA012018_99_ dooo1deooo1", acessível no Arquivo Nacional (pesquisa feita em 12 maio 2016).

50 art. $1^{\circ}$ da Lei no 11.430/2006 acrescenta 0 art. 21-A à Lei $n^{\circ} 8.213 / 91$, cujo texto é 0 seguinte: "A perícia médica do INSS considerará caracterizada a natureza acidentária da incapacidade quando constatar ocorrência de nexo técnico epidemiológico entre o trabaIho e o agravo, decorrente da relação entre a atividade da empresa e a entidade mórbida motivadora da incapacidade elencada na Classificação Internacional de Doenças - CID, em conformidade com o que dispuser o regulamento". 
maior será o número, após perícias, das concessões de benefícios de auxílio-acidente.

4. Se a quantidade de concessões do auxílio-acidente decorrente de acidente de trabalho no último ano do governo Fernando Henrique Cardoso representa $84 \%$ do número de concessões do primeiro ano do seu governo, do primeiro ao último ano do governo Lula, o número de concessões de auxílio-acidente decorrente de acidente de trabalho aumentou pouco mais de $44 \%$.

5. A média anual de concessões de aposentadorias por invalidez por acidente de trabalho aumentou em 70,77\% no governo Fernando Henrique Cardoso em relação à média anual no governo Itamar Franco, e aumentou em Io,65\% no governo Lula em relação à média do governo Cardoso.

Esse é um dado que pode indicar uma redução na agressividade dos efeitos dos eventos acidentários ao longo do governo Lula, decorrente de vários fatores, e aqui arrisco três deles: i) uma maior exigência do trabalhador e dos sindicatos das categorias profissionais em relação a condições de trabalho saudáveis; ii) um maior receio do patronato quanto aos custos previdenciários e às condenações judiciais em ações trabalhistas; ${ }^{6}$ e iii) um maior rigor de órgãos públicos, como o Ministério do Trabalho e Emprego e o Ministério Público do Trabalho, no acompanhamento das condições de trabalho.

6. A concessão de pensão por morte decorrente de acidente de trabalho caiu mais de $54 \%$ no governo Cardoso e quase $60 \%$ no governo Lula. E no governo Dilma Rousseff, a redução foi ainda mais acentuada.

6 Em 2004, a Emenda Constitucional n 45, conhecida como "Reforma do Judiciário", determinou como competente o tribunal trabalhista para a apreciação e o julgamento de ações relacionadas aos danos decorrentes dos ambientes de trabalho à saúde do trabalhador, 0 que aumentou muito o número de condenações judiciais contra empresas que geravam acidentados e adoentados do trabalho. 
7. Tomando-se a média do governo Lula, na comparação com um único ano do governo Dilma, verifica-se um aumento nas duas modalidades de auxílio-acidente. Esse crescimento é notado ainda na concessão da aposentadoria por invalidez acidentária e no auxílio-doença, com apenas decréscimo, aliás significativo, no número de concessões de pensão por morte.

8. No período do governo Dilma Rousseff, manteve-se o ritmo de crescimento nas concessões do auxílio-acidente, mesmo tendo ocorrido uma pequena queda de 2013 a 20I4, inclusive da aposentadoria por invalidez e do auxílio-doença acidentário. Se essa queda revela uma tendência, é caso de estudo posterior.

O enfrentamento aos agravos à saúde do trabalhador deveria ser uma política permanente e contínua do Estado brasileiro, mas se revela reflexo de políticas de governos, como algo circunstancial. E os governos seguem modelos próprios: enquanto no período assumidamente neoliberal (do ex-presidente Fernando Henrique Cardoso) predominavam convênios terceirizados em perícias do INSS, cuja orientação talvez caminhasse para um tímido registro dos acidentes de trabalho, mas com prolongados afastamentos quando reconhecidos o nexo causal e a incapacidade laboral, no período imediatamente posterior (do ex-presidente Lula), os peritos compuseram a carreira estatutária de servidores públicos do INSS, e houve, a partir daí, maior cuidado no registro dos acidentes do trabalho e afastamentos menos prolongados. A mudança foi acompanhada pela posterior adoção do nexo técnico epidemiológico, conforme mencionado.

Pelos registros dos benefícios decorrentes de acidentes de trabalho, verifica-se uma redução daqueles vinculados aos efeitos mais nefastos: a morte (justificadora da pensão por morte) e a incapacidade total e permanente (justificadora da aposentadoria por invalidez). Por outro lado, houve aumento das concessões de benefícios relacionados a efeitos menos graves: a incapacidade parcial e 
temporária (auxílio-doença) e a incapacidade parcial e permanente (auxílio-acidente). Infere-se, assim, que as sequelas incapacitantes estariam mais presentes no cotidiano das relações de trabalho.

Supõe-se um certo distanciamento dos dados reais aos registros formais da Previdência Social. Quanto mais próximo chegarmos aos números reais, maior a possibilidade de a sociedade melhor se instrumentalizar e pressionar o Estado a implantar efetivas políticas preventivas e de redução de acidentes e doenças do trabalho.

Os silêncios, omissões e equívocos governamentais em políticas de saúde do trabalhador não devem, no entanto, ser justificados pelo não conhecimento da realidade, por incompetência de dirigentes ou pelo singelo, ideológico e autoexplicativo jargão midiático de "falta de vontade política".

Neste livro, os dados coletados em anuários estatísticos limitam-se no tempo até o final do primeiro governo da presidenta Dilma Rousseff, isto é, dezembro de 20I4. O processo político que se sucedeu a partir daí e que provocou o golpe parlamentar de 20I6, com a guinada ao poder do vice-presidente Michel Temer (PMDB), foi acompanhado de alterações relevantes com efeitos no mundo do trabalho, em especial com o forte aumento do desemprego. Houve, então, como fruto do modelo adotado após o golpe e com tendências ao aprofundamento das desigualdades sociais (BIAVASCHI, 20I6), grande redução de verbas públicas em diversos programas voltados para a proteção social, como a fiscalização contra a exploração de trabalho análogo a escravo, que auxiliava no combate à precarização e à superexploração do trabalho. Pesquisas futuras detalharão os resultados dessa situação, embora alguns sejam perceptíveis, como o aumento de população em situação de rua nos centros urbanos e a violência em conflitos de terras no campo. Esses fatos ilustram o quanto mudanças governamentais podem provocar turbulências em políticas sensíveis como a previdenciária. 
Enfim, os acidentes compõem o mundo do trabalho e são reveladores ou termômetros do grau de exploração da força de trabalho em uma sociedade. Sendo assim, algumas hipóteses podem ser esboçadas: revelar e divulgar ocorrências de acidentes de trabalho em um período em que se busca incentivar empreendimentos industriais podem não fazer parte do cardápio dos interesses industriais; ou: no esforço de não se saber o que acontece na realidade, quanto mais distante estivermos de denúncias graves sobre acidentes, como os das aparentemente inseguras minas na China, mais teremos a impressão de que são fenômenos que pouco ocorrem por aqui, onde as condições seriam supostamente mais seguras - em que pesem casos como o da explosão da fábrica de fogos de artifício no município baiano de Santo Antônio de Jesus em 1998, que ceifou 64 vidas, ou o da queda de um elevador em prédio em construção em Salvador, em 20II, que eliminou nove trabalhadores, entre outros tantos exemplos relacionados aos autodenominados empreendimentos econômicos.

Os registros de acidentes também sofrem alterações a depender da norma positivada. Se a adoção do nexo técnico epidemiológico a partir de 2007 permitiu maior aproximação entre registros e realidade, no passado, a Lei no 6.367/76 transferiu a cobertura previdenciária dos acidentados afastados por menos de 15 dias às empresas, o que fez cair os registros oficiais de acidentes. (COHN et al., 1985) Um "manejo" que falseou a realidade em um período em que as denúncias sobre condições perigosas e insalubres de trabalho eram reprimidas. ${ }^{7}$ Durante a Ditadura Civil-Militar de 1964 a 1985, os acidentes de trabalho eram subnotificados, alguns eventos sequer chegavam a ser classificados como relacionados ao trabalho,

7 Curioso que a Lei no 6.367/76 enquadrava como acidente de trabalho a vítima de "ato de sabotagem ou de terrorismo praticado por terceiros, inclusive companheiro de trabalho" (artigo $2^{\circ}$, parágrafo $1^{\circ}$, inciso III, alínea "a" da Lei n 6.367/76), em nítida alusão aos atos de resistência que ocorriam na época contra a Ditadura Militar. 
como a violência política patronal sofrida contra dirigentes sindicais $^{8}$ ou contra trabalhadores rurais em regiões isoladas e distantes dos grandes centros. ${ }^{9}$

\section{A necessária discussão sobre a saúde do trabalhador e o direito ambiental do trabalho: reflexões para subsídios e contribuições}

Antes mesmo das reflexões propostas para este item, é propícia a provocação que encerra o texto de Matta e colaboradores (20II, p. 196): "Refletir sobre o método aplicado à legislação previdenciária acidentária, num outro modelo de teoria e ação de políticas públicas sistematicamente vinculadas à defesa da saúde nos processos produtivos, é um desafio que o país ainda não encarou".

O aprofundamento de debates e pesquisas sobre o ambiente de trabalho pode auxiliar no clareamento da postura do Estado sobre acidentes do trabalho e o enfrentamento político do problema, com o esforço mais incisivo do poder público tanto em melhor quantificá-lo e conhecê-lo, quanto em identificar e punir responsáveis por acidentes e doenças do trabalho. Nesse sentido, Carlos Minayo Gomez considera que a saúde do trabalhador tem obtido mais espaços e visibilidade, seja pela "vasta e crescente produção científica sobre temas próprios da relação trabalho-saúde", seja porque "no espaço institucional do SUS vem apresentando um contínuo crescimento nos últimos anos, particularmente no nível assistencial". (GOMEZ, 2OII, p. 30-3I)

8 Neste sentido, conferir o documento datado de 1985 e acessível no Arquivo Nacional registrado sob o código "ARE_ACE_6869_85", que trata de denúncia da Organização Internacional do Trabalho (OIT) contra o governo brasileiro, referente a violências contra trabalhadores rurais na Paraíba (pesquisa realizada em 12/05/2016).

9 O Informe n 302/84, da Divisão de Segurança e Informações do Ministério do Trabalho, documento acessível no Arquivo Nacional, sob o código "AC_ACE_46757_84", tem como assunto denúncias sobre exploração do trabalho humano no interior do estado do Ceará, com a anuência de CIPAs manipuladas por empresas (pesquisa realizada em 12/05/2016). 
Se há avanços práticos e teóricos na área da saúde, no campo jurídico, no entanto, a temática anda a passos muito lentos: a saúde do trabalhador ainda não é assumida integralmente pelo direito do trabalho que, por sua vez, tem dificuldade, assim como o direito previdenciário, na aproximação com o direito ambiental para compreender de forma ampla a complexidade do ambiente de trabalho. Mas há esforços para a superação dessa emblemática equação. É o que parece sugerir reflexões recentes sobre o direito ambiental do trabalho, campo que articula as diferentes áreas de conhecimento que o constitui e com as quais necessita dialogar incessantemente.

O direito ambiental marca o final do século XX de maneira irreversível: a discussão sobre a matéria penetra nas legislações internas e internacionais fixando deveres, direitos e responsabilidades dos estados e da sociedade. Em um contexto de valorização de princípios, aqueles específicos do direito ambiental são divulgados tais quais as normas que o regulamentam. Definição precisa é proposta por Maurício Godinho Delgado (2009, p. I73): “os princípios jurídicos despontam, assim, como sínteses conceituais de nítida inserção histórica, submetendo-se a uma inevitável dinâmica de superação e eclipsamento, como qualquer outro fenômeno cultural produzido"

No caso, os princípios chegam a se confundir com as regras no tocante ao significado do ambiente e à responsabilidade pela manutenção de ambientes saudáveis. Ao deixar de discutir apenas sobre a poluição como algo inexorável e avaliar sobre culpados por essa situação, a sociedade movimenta-se em conformidade com os cuidados propostos nos princípios do direito ambiental. É nesse sentido que sua assunção enquanto matéria jurídica exige uma espécie de legitimação civilizatória do que propõe como princípios, que passa a tomar forma de normas posteriormente, a exemplo do conciso e eficiente art. 225 da Constituição. 
Princípios do direito ambiental auxiliam a compreensão de eventos relacionados ao ambiente do trabalho. Assim, são relevantes aqueles que indicam a preocupação por um desenvolvimento sustentável, a garantia de participação da sociedade na defesa do meio ambiente, a precaução, a prevenção e a responsabilidade objetiva do poluidor em pagar pelos danos.

Para essa análise, toma-se como paradigma o conjunto de observações e conclusões elaboradas em pesquisa científica intitulada "Direito e Política: Estudos de casos sobre meio ambiente do trabalho na Bahia", desenvolvida na Universidade Estadual de Feira de Santana (UEFS), que analisou diferentes eventos: I) a população de Santo Antônio de Jesus testemunhou uma explosão em uma fábrica clandestina de fogos de artifício, em I998, que resultou em quase 90 mortes; 2) os munícipes de Bom Jesus da Serra, que sediou por 30 anos uma mina de amianto, e os de Simões Filho, onde funciona uma fábrica da Eternit que utiliza amianto, sofrem com vários casos de doenças respiratórias; 3) os operários do complexo Polo Petroquímico de Camaçari convivem com o cancerígeno benzeno, uma das matérias-primas da cadeia produtiva; e 4) em Santo Amaro da Purificação, cidade onde por cerca de 30 anos funcionou uma fábrica de chumbo, trabalhadores e população circunvizinha forma vítimas de gravíssimas doenças.

Todos esses eventos impactantes que ocorreram na Bahia - mas situações similares podem ser encontradas em outros estados da federação - referem-se diretamente aos efeitos deletérios sobre a saúde dos trabalhadores e que podem nos dizer muito. Seguem, abaixo, descrições sobre cada um deles - expostos ao amianto (a), vítimas de explosão (b), contaminados por benzeno (c) e pelo chumbo (d):

a. A exposição dos trabalhadores mineiros - na mina São Felix do Amianto, iniciada em I939 e desativada em I969, em Bom Jesus da Serra, região do semiárido baiano - e industriários - na fábrica Eternit, em Simões Filho, região metropolitana de Salvador - ao 
amianto é de responsabilidade daquele que extrai, explora, adquire e refina a fibra mineral. Ambas, a mina e a fábrica, compõem o patrimônio da empresa multinacional SAMA. Se ao contratar pessoas para trabalhar na extração e refino do amianto ou no fabrico de mercadorias que contenham a fibra, a mina e a empresa deixam de informar ao trabalhador sobre o risco da exposição, identifica-se situação ilícita que revela a má-fé daquele que sabia do risco, em proveito da desinformação dos que se submeteram à exposição. A empresa poderia informar sobre o ambiente não saudável - os primeiros registros no mundo de cânceres decorrentes da exposição ao amianto datam de antes de inaugurada a mina - e fornecer equipamentos de proteção aos trabalhadores para a prevenção de danos. Se, assim mesmo, os equipamentos se afiguram como inadequados ou insuficientes (como no caso do amianto), fica mantida a postura negligente de manutenção de ambiente não saudável (em afronta ao art. 225 da Constituição), pois no caso da mina, poderia ser desativada, e no caso da fábrica, ser utilizado outro tipo de material, substituto do amianto.

Considerando que se trata de um cenário ambiental, a responsabilidade do poluidor pela exposição é objetiva, isto é, independe de demonstração de culpa ou de dolo do poluidor. No caso, os poluidores (a mina e a empresa) são os responsáveis pelos danos decorrentes dos ambientes não saudáveis que produziram. (FREITAS, 20I5) A forma de averiguação dessa poluição, na realidade, não levou em conta, infelizmente, o cuidado previsto em normas a mbientais, e os efeitos nefastos apresentam-se sob a forma de casos de asbestoses, placas pleurais e cânceres entre os trabalhadores nesses ambientes, repetindo-se o que ocorreu e ainda ocorre em outras regiões do planeta, como na cidade italiana de Casale Monferrato. (ROSSI, 20IO)

No caso específico da mina desativada em Bom Jesus da Serra, o Ministério Público Federal e o Ministério Público Estadual 
ajuizaram, conjuntamente, em 2009, ${ }^{10}$ ação civil pública para que a empresa assumisse a responsabilidade pela degradação ambientação do local e ameaça à saúde dos habitantes. Após uma longa e densa instrução processual, o Juiz Federal João Batista de Castro Júnior, da I $^{\text {a }}$ Vara da Subseção Judiciária de Vitória da Conquista prolatou, em 20I7, sentença exemplar,11 pelo aprofundamento na fundamentação jurídica e articulação entre fatos históricos e provas, condenando a SAMA no pagamento de 500 milhões de reais a título de danos morais, e mais 50 mil reais a título de danos morais individuais. A decisão deve ser considerada um marco em termos de atenção jurídica e judiciária ao direito ambiental, aí incluído o direito ambiental do trabalho. A sentença se compõe como uma significativa revisão bibliográfica acerca dos malefícios do amianto na saúde humana e se torna emblemática por dar concretude e visibilidade à questão. Afinal, trabalhar sob a exposição do amianto se constitui em reconhecida atividade de risco, por se tratar de mineral considerado pela legislação ambiental nacional como resíduo perigoso, de acordo com a Resolução nº 348 do Conselho Nacional do Meio Ambiente (CONAMA).

b. Cabe a quem explora economicamente o fabrico de fogos de artifício arcar com os riscos dessa atividade, seja no aspecto trabalhista, como dispõe o Art. $2^{\circ}$ da CLT, seja quanto à questão propriamente dita da fabricação de explosivos (conforme o Decreto-Lei $n^{\circ} 4.238 / 42$, que "dispõe sobre a fabricação, o comércio e o uso de artigos pirotécnicos e dá outras providências"), ou ainda quanto ao regulamento da Lei ambiental.

10 Para mais informações conferir: <http://www.prba.mpf.gov.br/mpf-noticias/meio-ambiente-e-patrimonio-cultural/mpf-e-mpe-ba-ajuizam-acao-civil-publica-contra〉. Trata-se de ação tombada sob o nº 2009.33.07.000988-3.

11 Para o acesso à sentença, acessei o site da Associação Brasileira dos Expostos ao Amianto, em agosto de 2017. 
Antes mesmo de se observar essas regras é necessário o máximo de respeito à saúde, bem tutelado constitucionalmente e à integridade física e mental das pessoas, como direitos da personalidade garantidos pelo Código Civil.

Por se tratar de explosivos, o risco de destruição ambiental existe e a precaução deve ser conduta rigorosamente adotada como princípio jurídico. Assim, havendo acidente ambiental por conta da atividade (como foi o caso em Santo Antônio de Jesus, cidade localizada no recôncavo baiano), o seu responsável deve assumir os prejuízos provocados pelo evento, sejam as suas vítimas empregadas ou não do empreendimento. O risco da atividade em si convoca o dispositivo do art. 927, parágrafo único, do Código Civil, que prevê a aplicação da responsabilidade objetiva, e que se articula a um outro princípio ambiental: o compromisso do poluidor em pagar pelos efeitos da poluição.

A qualidade de explosivo é considerada perigosa, como dispõe a Convenção sobre o Controle de Movimentos Transfronteiriços de Resíduos Perigosos e seu Depósito, conhecida como Convenção da Basiléia, introduzida no direito nacional pelo Decreto no 875/93.

As ações judiciais movidas pelas famílias das vítimas têm gerado condenações contra o Exército Brasileiro, o Estado da Bahia e a empresa, que respondem solidariamente pelas indenizações. ${ }^{12}$ Já os responsáveis pelas atividades foram condenados criminalmente na Vara do Tribunal do Júri. ${ }^{13}$ Não há notícias, porém, de ações que reclamem benefícios previdenciários junto ao INSS.

c. O benzeno faz parte da produção petroquímica. A discussão quanto à prevenção aos riscos provocados pela exposição ao benzeno se desenvolveu no Polo Petroquímico de Camaçari com certo

12 Conferir em: 〈http://trf-1.jusbrasil.com.br/noticias/111917215/uniao-e-do-estado-da-bahia-devem-indenizar-parentes-de-vitimas-de-acidente-em-fabrica-de-fogos-de-artificio>.

13 Conferir em: <http://atarde.uol.com.br/bahia/noticias/1779925-familiares-de-vitimas-de-explosao-ainda-lutam-por-justica>. 
atraso e a partir da pressão do movimento sindical, que alegava a existência de um passivo de trabalhadores doentes e mortos. A preocupação era apurar com rigor a quantidade de partículas de benzeno no ar e obrigar as empresas a estabelecer um maior controle dos equipamentos industriais, além de instituir monitoramentos constantes na saúde dos trabalhadores. Duas questões podem ser levantadas com apoio na reflexão do direito ambiental e que afetaram e afetam as pessoas que ali trabalharam e trabalham: uma, é que as empresas sempre souberam do potencial de agressividade do benzeno e de outros produtos que compõem a cadeia industrial específica e que apenas se mobilizaram para adotar medidas de segurança após a pressão operária; duas, é que essas medidas acabaram por ser mitigadas pelo esvaziamento da quantidade de trabalhadores diretamente admitidos pelas empresas e pelo aumento dos contratados por empresas terceirizadas e empreiteiras, o que reduziu o controle e as informações sobre os expostos.

O princípio da prevenção, ao qual as empresas estavam obrigadas, poderia ter sido exercido de maneira pontual e bem mais eficaz e eficiente. Os debates sobre o benzeno em Camaçari e em outras regiões petroquímicas do país suscitaram a necessidade de acompanhamento mais cuidadoso por parte do Ministério do Trabalho, o que originou um grupo de trabalho específico, a Comissão Nacional Permanente do Benzeno (CNPBz), que tem elaborado normativas a fim de reduzir as possibilidades de exposição. Nessa linha, o governo federal produziu um protocolo que afirma ser o benzeno "um mielotóxico regular, leucemogênico e cancerígeno, mesmo em baixas concentrações", ${ }^{14}$ cuja exposição, portanto, provoca riscos. Individualmente, alguns dos trabalhadores afetados

14 Documento em versão para consulta pública de 15/02/2005, elaborado por A. Arcuri e outros, encontrava-se em site específico do Ministério do Trabalho. 
pela exposição recorreram ao judiciário em busca de indenizações contra empresas e de benefícios contra o INSS.

d. A indústria que refina e beneficia o chumbo deve manter um local de descarte do lixo decorrente da produção fabril. O local de descarte e a produção em si são de responsabilidade da indústria e não deve poluir, entendendo-se também como tal a poluição ambiental do trabalho, isto é, que afeta os trabalhadores.

Em Santo Amaro da Purificação, outra cidade do Recôncavo Baiano, a indústria que refinava o minério de chumbo oriundo da Chapada Diamantina produziu uma tamanha quantidade de lixo que, com o tempo, formou montanhas de escórias. É como se os morros que formavam a serra em Itabira, desaparecidos pela exploração industrial do ferro, fossem transportados para Santo Amaro - sem que o poeta Carlos Drummond de Andrade ${ }^{15}$ imaginasse. Após encerrada a atividade fabril, o chumbo contido no lixo industrial permaneceu acumulado de forma inadequada, de modo que ao longo dos anos contaminou pessoas que trabalhavam na fábrica e que moravam próximas às suas instalações.

O chumbo consta do Anexo I da Convenção da Basiléia, na categoria de resíduos a serem controlados. Não foram apurados casos judiciais que buscavam benefícios previdenciários, embora existam ações indenizatórias contra a empresa.

Os produtos envolvidos nos casos acima (amianto, explosivos, benzeno e chumbo) indicam exposição ou contaminação como evidentes riscos aos trabalhadores: independentemente de empregados do agente econômico responsável pela atividade industrial, se incluem no risco o trabalhador terceirizado ou aquele cidadão envolvido em alguma atividade de prestação de serviços que percorre o ambiente eventualmente afetado por chumbo, benzeno ou amianto. Em todos os casos, é também possível encontrar pessoas

15 Da falta que faz a serra em Itabira para Drummond, ler a poesia "A montanha pulverizada". 
vitimadas pela poluição que não trabalhavam naqueles ambientes, mas que circulavam ou moravam próximos de um ambiente não saudável - aspecto mais perceptível nos casos do amianto a céu aberto na mina desativada em Bom Jesus da Serra ou no chumbo espalhado por Santo Amaro da Purificação, que revelam a completa inexistência de uma prática real de desenvolvimento sustentável por parte das empresas e de fiscalização efetiva pelos vários órgãos da administração pública.

É diante desse cenário que o direito ambiental do trabalho pode contribuir para proporcionar reflexões mais complexas caracterizadas pela interdisciplinaridade e pautadas em uma interseção de áreas distintas. Nesse sentido, o direito ambiental do trabalho foge da fragmentação de conhecimentos específicos, e para situar o seu objeto é necessário partir do direito constitucional, promover o diálogo entre o direito ambiental e o direito do trabalho, com explícita extensão ao direito previdenciário e ao direito à saúde, de modo a permitir articular elementos e princípios próprios, sem que se afaste do universo científico que compõe a saúde do trabalhador.

No que diz respeito ao sujeito, isto é, à pessoa ou à comunidade afetadas ou em risco em face do ambiente de trabalho, titulares do direito à vida digna em toda a abrangência que isso signifique ou simbolize, o direito ambiental do trabalho projeta a importância do direito constitucional, com a altivez que a vida digna passou a ter contemporaneamente, além do direito civil (em especial aqueles vinculados à personalidade) e do direito penal, na perspectiva de proteção e prevenção a condutas criminosas, sem perder de vista as contribuições fundamentais de normas internacionais, não limitadas às regras oriundas da Organização Internacional do Trabalho (OIT), mas de todos os demais organismos, sempre cobertos pelo manto da proteção aos direitos humanos.

Em vista dos princípios fundamentais da Constituição, o Estado deve envolver-se na construção de uma sociedade justa e soli- 
dária, com valorização da cidadania, o que convoca o ordenamento jurídico nacional a proteger a pessoa quando seu bem-estar - incluído nesse universo a saúde do trabalhador - é colocado em risco. A leitura articulada e entre si complementar dos artigos 200 e 225 da Constituição sugere que saúde do trabalhador e ambiente vinculam-se necessariamente em favor, exatamente, do bem-estar daquele que vive para o trabalho enquanto se encontra trabalhando, como a dar suporte àqueles aspectos fundamentais da própria Constituição. Dessa síntese, é possível pontuar os elementos de um direito ambiental do trabalho, enquanto área de conhecimento, que se implica necessariamente à realidade concreta do mundo do trabalho.

O direito ambiental do trabalho relaciona-se à defesa da pessoa em uma situação de trabalho, independentemente do tipo de vínculo - emprego, autônomo, servidor público ou outras situações possíveis. A pessoa, na qualidade de trabalhador, tem direito a um ambiente saudável. O agente responsável pelo ambiente, como o empregador na hipótese do contrato de trabalho, o é também e de maneira objetiva, quanto aos riscos à vida e à saúde do trabalhador. Isso implica que a garantia de um ambiente saudável é inerente à proteção geral da vida digna. Sendo esse ambiente o do trabalho, a questão não se afasta do que dispõe o art. 225 da Constituição exatamente pelo dispositivo do art. 200, VIII - "Ao sistema único de saúde compete, além de outras atribuições, nos termos da Lei: [...] colaborar na proteção do meio ambiente, nele compreendido o do trabalho". (BRASIL, I988)

A fragmentação em diferentes áreas jurídicas dificulta a leitura e a interpretação, a partir do direito, das questões da vida, sejam elas das mais simplórias às mais complicadas. A visão articulada propõe aproximar o direito à realidade. No caso concreto, a contribuição jurídica à complexa questão ilustrativa do amianto exige essa articulação, que toma a forma do interdisciplinar direito am- 
biental do trabalho, compreendido em uma perspectiva de direito constitucional à saúde e que comunga posições com o direito trabalhista, civil, previdenciário e, especialmente, o ambiental.

O direito é essencialmente fruto do conflito de interesses. O estabelecimento de uma razão jurídica na sociedade é precedido de disputas entre contrários. O reconhecimento explícito dessa relação entre direito e conflito se sobressai em contextos não autoritários. No Brasil, no período posterior à Ditadura Civil-Militar (1964/1985) e à Constituição, mesmo sem justiça de transição, percebe-se a ascensão de movimentos sociais e de projetos alternativos de poder, o que mostra a relação entre direito e conflito de maneira dinâmica, e a presença de direitos insurgentes. (BALDEZ, 20IO)

As audiências públicas no Supremo Tribunal Federal para discutir o banimento, ou não, do amianto no país, são, nesse sentido, simbólicas, tais como foram as audiências sobre a Reserva Raposa Serra do Sol, sobre as pesquisas em células-tronco, a política das cotas no STF; e ainda sobre a terceirização no TST: o saber jurídico revelou suas limitações e admitiu as contribuições provocadas pelas investigações pautadas na interdisciplinaridade, com uso eventual do empírico. ${ }^{16}$ São as quebras de paradigmas, mesmo que tardiamente, batendo às portas do direito, sem às vezes pedir licença.

Outra faceta dessas mudanças se dá com a emergência dos princípios jurídicos enquanto ferramentas norteadoras para a interpretação dos direitos. A adoção dos princípios seria uma tendência pós-positivista, de maneira que o retórico de outrora passou a ter força substantiva. Dito de outra forma: a norma em si pode dispor do direito, mas ser inócua na sua aplicação, pois desacompanhada dos instrumentos necessários para tanto, o que reflete o interesse pela sua inocuidade; esses instrumentos podem ser construídos

16 Sobre o tema, há recente contribuição da Rede de Pesquisa Empírica em Direito (RRED) em Machado (2017). 
culturalmente a partir de interpretações da sociedade, geradas em conflitos, e daí originarem-se não outras normas, mas princípios que dirijam as normas. Uma dinâmica que tende a afastar a norma da retórica inócua e dar-lhe substância no sentido de aplicabilidade. No caso concreto, vida digna deixa de ser um direito retórico e passa a algo substantivo, a partir da sua valorização enquanto princípio. O que se discute é o direito fundamental a uma vida digna ao trabalhador, em toda a sua concreção e extensão, em uma perspectiva de ultrapassar interpretações limitadoras e positivistas do direito do trabalho, como algo imobilizador do que realmente significaria o pleno respeito àquele que vive diretamente do trabalho.

Do princípio da vida digna, derivam outros. No campo do direito ambiental do trabalho, cabem os princípios oferecidos pelo direito ambiental, plenamente aplicáveis às relações do trabalho na perspectiva de proteção à saúde do trabalhador.

Não há vida digna sem saúde. O direito ambiental do trabalho entrelaça o direito à saúde ao do direito do trabalho. Nesse campo da vida digna, articula-se o que temos acumulado sobre os direitos humanos. Nesse sentido, José Antônio Ribeiro de Oliveira Silva (2008, p. 68) constrói a seguinte reflexão:

Esse direito humano à saúde é dotado de um conteúdo essencial, identificado nas condições mínimas que devem ser atendidas para a sua satisfação, já que componente do rol das necessidades básicas do ser humano. [...]

De igual modo, o direito à saúde do trabalhador também é dotado de um conteúdo essencial, conquanto extenso, configurando um direito individual subjetivo à sua proteção.

A discussão traz à baila o posicionamento de Pádua Fernandes (2009, p. 67): "A interpretação dos direitos humanos deve guiar-se pela busca de efetividade da ação humana, simultaneamente como garantia e expressão da liberdade. Porque devem ligar-se à ação, os direitos humanos têm no direito de resistência o seu referencial." 
O conteúdo essencial comporia, assim, o patamar legal mínimo sobre o qual se pautariam as garantias, que combinado a uma referência do direito da sociedade à saúde pública, se articularia um direito ambiental do trabalho. Há normas que compõem esse mínimo, o que importa, pois, é superar a fragmentação imposta à interpretação dessas normas e bem articulá-las, de modo a dar concretude ao direito ambiental do trabalho especialmente a partir do direito do trabalho. As conclusões de Raimundo Simão de Melo (20I0, p. 36-37) se aproximam dessa síntese:

No Direito do Trabalho, o bem ambiental envolve a vida do trabalhador como pessoa e integrante da sociedade, devendo ser preservado por meio da implementação de adequadas condições de trabalho, higiene e medicina do trabalho. Cabe ao empregador, primeiramente, a obrigação de preservar e proteger o meio ambiente laboral e, ao Estado e à sociedade, fazer valer a incolumidade desse bem.

As vítimas da explosão em Santo Antônio de Jesus, da contaminação pelo chumbo e cádmio em Santo Amaro da Purificação, do benzeno em Camaçari e da exposição ao amianto, assim como de outros eventos emblemáticos, figuram como pessoas cujos direitos deixaram ou deixam de ser reconhecidos por aqueles que têm a posição de evitar acidentes ou doenças do trabalho; uma posição, portanto, de poder, seja ele patronal, no caso da empresa responsável pelo evento de degradação à saúde do trabalhador, ou de Estado, na hipótese de poder público que permite um cenário de não reconhecimento de direitos.

A não afirmação de direitos não significa que inexista cobertura legal ou constitucional a defender os interesses das vítimas de acidentes ou doenças do trabalho, pois, afinal, há normas e princípios que permitem a proteção e a prevenção. Mas a indiferença em relação a esses direitos pode indicar o predomínio de uma compreensão política voltada aos interesses de dado modelo de desenvol- 
vimento que, combinado a uma dada interpretação jurídica, envolva a sociedade em uma perspectiva de progresso não sustentável e uma exploração naturalizada do trabalhador que comprometa a sua saúde ou a sua vida.

Os casos estudados na pesquisa mencionada apontam para essa conclusão. No entanto, a valorização do direito ambiental do trabalho, que por meio de um aprofundamento interdisciplinar permite uma contribuição efetiva para o deslinde de questões como a responsabilidade sobre agressões à saúde do trabalhador, indica uma reação importante, que necessariamente se origina e se fortalece a partir da movimentação social em torno dos interesses dos trabalhadores em defesa da saúde e da vida. Aí se insere a preocupação em revelar os números e dados qualitativos sobre os acidentes de trabalho, área em que o direito previdenciário possui um domínio singular. Nesse aspecto, investigar o auxílio-acidente como benefício relacionado a acidente de trabalho ganha relevância, pelas possibilidades que oferece para uma visão mais ampla e articulada sobre os efeitos do acidente.

É possível ainda considerar que o esforço público em apurar os dados previdenciários dos acidentes e doenças do trabalho não se mostra ainda suficiente para se conhecer plenamente a realidade brasileira, embora parte significativa esteja contemplada nos registros tabulados pelo INSS. No tocante ao auxílio-acidente decorrente de acidente de trabalho, a quantidade de trabalhadores sequelados com capacidade laboral reduzida parcial e permanentemente registrada nos dados da previdência social pode, assim, não refletir a realidade. Como percebido na ilustrativa pesquisa, são muitas as formas de burlar situações tipicamente acidentárias, e que sequer chegam aos postos da previdência ou não são enquadradas como tais. No capítulo anterior, viu-se, nesse universo, que os acidentes de trânsito eventualmente deixam de ser considerados como laborais. 
Enfim, há também um esforço da própria sociedade em buscar conhecer mais seus direitos no âmbito previdenciário. Os números, ao longo dos anos, sugerem que o trabalhador vem tomando mais cuidado no cotidiano laboral, fator que, junto a outros, tem provocado a queda na quantidade de infortúnios geradores de pensões por mortes decorrentes de doenças ou acidentes do trabalho. Em paralelo, o aumento de concessões de aposentadoria por invalidez e auxílio-acidente decorrentes de acidentes do trabalho sugere, de certa forma, um segurado mais consciente acerca dos benefícios oferecidos pelo INSS, embora prevaleça a desconfiança de que esse aumento ainda não reflita a quantidade real e as necessidades dos trabalhadores afetados por acidentes ou doenças do trabalho. 